\title{
Galectin-1 promotes basal and kainate-induced proliferation of neural progenitors in the dentate gyrus of adult mouse hippocampus
}

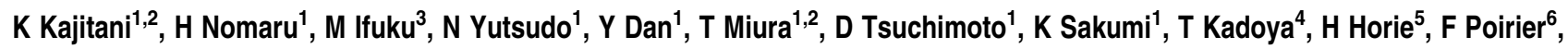 \\ M Noda ${ }^{3}$ and Y Nakabeppu ${ }^{*, 1}$
}

We examined the expression of galectin-1, an endogenous lectin with one carbohydrate-binding domain, in the adult mouse hippocampus after systemic kainate administration. We found that the expression of galectin-1 was remarkably increased in activated astrocytes of the CA3 subregion and dentate gyrus of the hippocampus, and in nestin-positive neural progenitors in the dentate gyrus. Quantitative reverse transcription PCR (RT-PCR) analysis revealed that the galectin-1 mRNA level in hippocampus began to increase 1 day after kainate administration and that a 13-fold increase was attained within 3 days. Western blotting analysis confirmed that the level of galectin-1 protein increased to more than three-fold a week after the exposure. We showed that isolated astrocytes express and secrete galectin-1. To clarify the significance of the increased expression of galectin-1 in hippocampus, we compared the levels of hippocampal cell proliferation in galectin-1 knockout and wild-type mice after saline or kainate administration. The number of 5-bromo-2'-deoxyuridine (BrdU)-positive cells detected in the subgranular zone (SGZ) of galectin-1 knockout mice decreased to $62 \%$ with saline, and to $52 \%$ with kainate, as compared with the number seen in the wild-type mice. Most of the BrdU-positive cells in SGZ expressed doublecortin and neuron-specific nuclear protein, indicating that they are immature neurons. We therefore concluded that galectin-1 promotes basal and kainateinduced proliferation of neural progenitors in the hippocampus.

Cell Death and Differentiation (2009) 16, 417-427; doi:10.1038/cdd.2008.162; published online 14 November 2008

Neurons are expected to survive and function throughout the lifespan of an individual; however, they are postmitotic and no longer proliferative, and are inevitably eliminated as a consequence of damage accumulated during aging. ${ }^{1}$ It is considered that there must be multiple mechanisms for maintaining neural networks in adult brains, including neurogenesis by which new neurons are supplied in restricted areas. ${ }^{2,3}$

It has been established that adult neurogenesis in rodents is enhanced after brain insults caused by ischemia ${ }^{4}$ and epileptic seizure. ${ }^{5}$ Insult to the brain likely triggers signals that activate expression of a set of genes, known as immediate early genes, in the hippocampus and cerebral cortex. ${ }^{6}$ Among many immediate early gene products, Jun and Fos family proteins function as components of transcription factor activator protein-1 complexes, ${ }^{7,8}$ and thus regulate transcription of various genes involved in cell proliferation, differentiation, and programmed cell death. ${ }^{6}$ We reported earlier that $\triangle \mathrm{FosB}$, an activator protein-1 subunit encoded by an alternatively spliced form of fos $B$ transcript, triggers quiescent cells to transit $\mathrm{G} 1$, initiate DNA replication, and ultimately undergo cell division, followed by such fates as proliferation, differentiation, and programmed cell death. ${ }^{9-12}$ $\Delta$ FosB is known to be chronically expressed in the dentate gyrus of hippocampus after ischemia, which is where and when neurogenesis takes place. ${ }^{13}$ We identified earlier a downstream target upregulated by $\Delta \mathrm{FosB}$, termed galectin-1, one of the major $\beta$-galactoside sugar-binding lectins in mammals. ${ }^{11}$ We further showed that this lectin regulates such cell fates as cell proliferation, differentiation, and death, as does $\Delta$ FosB. ${ }^{12-14}$ We thus consider that galectin-1 may also be involved in the regulation of neural cell fate. ${ }^{15}$

Galectin-1 is a ubiquitously expressed 14.5-kDa protein with a single carbohydrate-binding domain, and is a multifunctional

\footnotetext{
${ }^{1}$ Division of Neurofunctional Genomics, Department of Immunobiology and Neuroscience, Medical Institute of Bioregulation, Kyushu University, Fukuoka, Japan; ${ }^{2}$ Department of Neuropsychiatry, Graduate School of Medical Sciences, Kyushu University, Fukuoka, Japan; ${ }^{3}$ Laboratory of Pathophysiology, Graduate School of Pharmaceutical Sciences, Kyushu University, Fukuoka, Japan; ${ }^{4}$ CMC R\&D Laboratories, Kirin Pharma Co., Ltd., Takasaki, Japan; ${ }^{5}$ Research Center of Brain and Oral Science, Kanagawa Dental College, Yokosuka, Japan and ${ }^{6}$ The Department of Developmental Biology, Institute Jacques Monod, Universities Paris 6 and Paris 7, Paris, France

${ }^{*}$ Corresponding author: Y Nakabeppu, Division of Neurofunctional Genomics, Department of Immunobiology and Neuroscience, Medical Institute of Bioregulation, Kyushu University, 3-1-1 Maidashi, Higashi-Ku, Fukuoka 812-8582, Japan.

Tel: + 8192642 6800; Fax: + 8192642 6791; E-mail: yusaku@ @ioreg.kyushu-u.ac.jp

Keywords: galectin-1; adult neurogenesis; kainate; hippocampus; knockout mice; astrocyte

Abbreviations: BrdU, 5-bromo-2'-deoxyuridine; DCX, doublecortin; GCL, granule cell layer; GFAP, glial fibrillary acidic protein; IHC, immunohistochemistry; NeuN, neuron-specific nuclear protein; PSA-NCAM, polysialylated neural cell adhesion molecule; SGZ, subgranular zone; SVZ, subventricular zone

Received 17.9.08; revised 06.10.08; accepted 12.10.08; Edited by P Vandenabeele; published online 14.11.08
} 
molecule involved in the regulation of cell adhesion, cell proliferation, and programmed cell death. ${ }^{16-18}$ Galectin-1 is known to be involved in the growth and/or guidance of primary
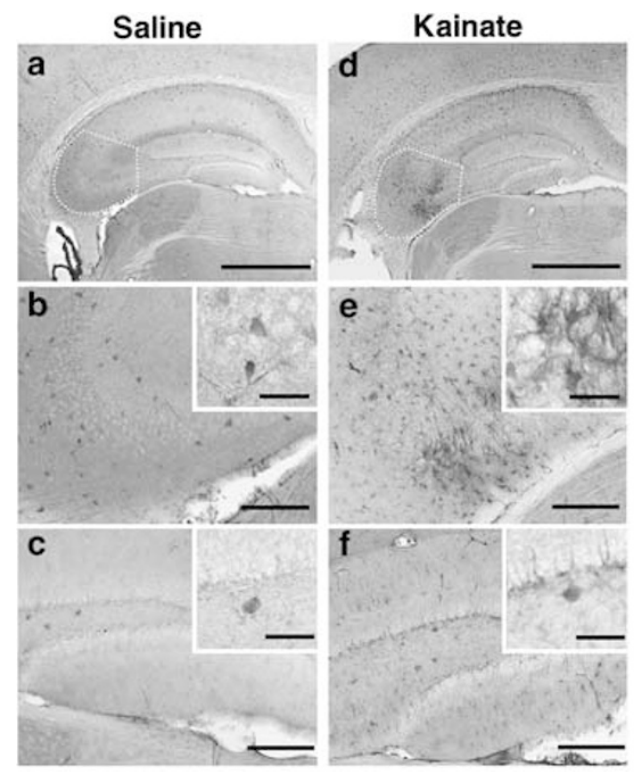

g

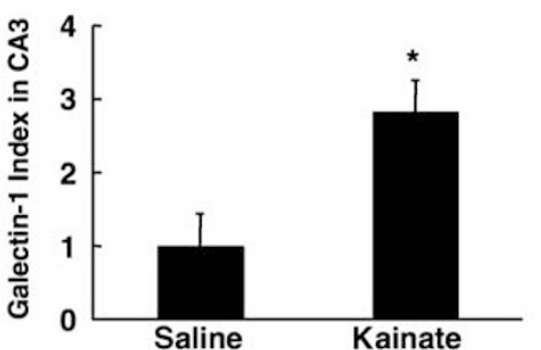

h

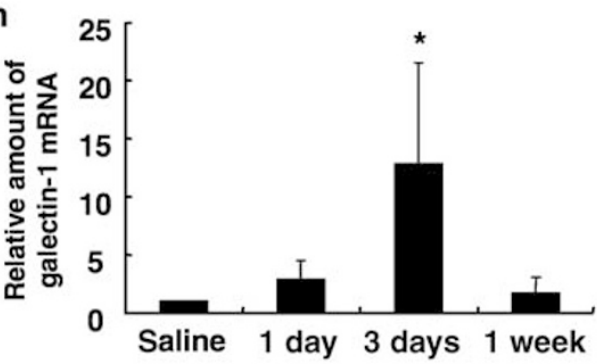

i

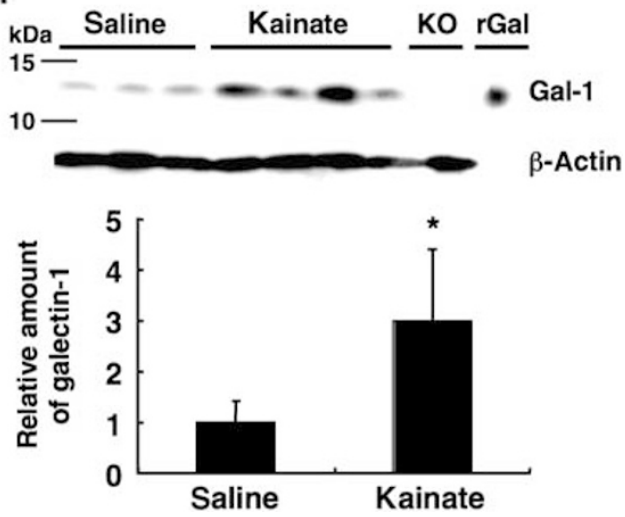

sensory olfactory axons, indicating that it plays a role in neural pathfinding in the mammalian nervous system. ${ }^{19}$ Furthermore, galectin-1 promotes axonal regeneration after axotomy in peripheral nerves of rat, ${ }^{20}$ suggesting that this lectin may participate in response to brain insult.

In this study, we examined the expression level of galectin-1 in the adult mouse hippocampus after systemic administration of kainate, an agent that produces epileptic seizures and enhances neurogenesis, in order to examine the role of galectin-1 in response to brain insult. Furthermore, we compared the extent of proliferation of neural progenitors in galectin-1 knockout and wild-type mice after kainate exposure.

\section{Results}

Systemic administration of kainate induces the expression of galectin-1 in the adult mouse hippocampus. To evaluate the expression of galectin-1 after brain insult, 10-week-old C57BL/6J mice were injected intraperitoneally with kainate $(30 \mathrm{mg} / \mathrm{kg})$ and were killed 1 week after injection. The brain sections were then prepared and subjected to immunohistochemistry (IHC). In the untreated mice, the expression of galectin-1 was detected in soma and, to a lesser extent, in neurites of large round neurons scattered in the hippocampus (Figure 1a-c). After 1 week of kainate administration, the population of galectin-1positive cells was significantly increased in the hippocampus, especially in the CA3 subregion and, to a lesser extent, in the dentate gyrus (Figure 1d-f). The immunoreactive signals were not observed in galectin-1 knockout mice with or without kainate administration (Supplementary Figure S1). We thus concluded that the expression of galectin-1 is inducible in the brain after kainate administration. In the CA3 subregion of the mouse hippocampus, the predominant expression of galectin-1 was observed in cells with multiple

Figure 1 Kainate-induced expression of galectin-1. (a-f) Immunohistochemical detection of galectin-1. Mouse brain sections were prepared 1 week after kainate administration (kainate), and were subjected to $\mathrm{IHC}$ to detect galectin-1. Untreated mice (saline) were injected with saline instead of kainate. Scale bars: a and $\mathbf{d}, 1 \mathrm{~mm}$; b, c, e and f, $200 \mu \mathrm{m}$; inset, $50 \mu \mathrm{m}$. (g) Quantitative analysis of galectin-1 expression induced after the exposure to kainate. Galectin- 1 immunoreactivity in the CA3 subregion as shown in the dotted area in panels a and $d$ relative to the value of the untreated group (saline) is shown as a bar graph with the mean \pm SD (salineinjected mice, $N=4$; kainate-injected mice, $N=5$ ). Unpaired $t$-test, ${ }^{*} P<0.01$. (h) Real-time RT-PCR analysis of galectin-1 mRNA. RNA was isolated from the dissected hippocampus at the indicated times after the injection of mice with kainate or 1 week after saline injection (saline), and was then subjected to real-time RT-PCR for galectin-1 (Gal-1) and GAPDH mRNA. The amount of galectin-1 mRNA determined by RT-PCR was normalized with that of GAPDH mRNA at each time point and the amount of the mRNA relative to that of the untreated group is shown in the bar graph as a mean $\pm S D$. Unpaired $t$-test, ${ }^{*} P<0.05$. ( $N=3$ mice per group). (i) Western blotting analysis of galectin-1 protein. Whole cell extracts of the mouse hippocampus obtained 1 week after kainate administration were subjected to western blotting analysis for galectin-1 (Gal-1) and $\beta$-actin. $\mathrm{KO}$, an extract from a galectin-1 knockout mouse; rGal, recombinant mouse galectin- $1 .{ }^{14}$ The amount of galectin-1 protein determined by western blotting was normalized with that of $\beta$-actin, and the mean value of the amount of galectin-1 relative to that of the untreated group (saline) is shown in the bar graph with the mean $\pm S D$. The control mice injected with saline $(N=3)$ and kainate-injected mice $\left(N=4\right.$ mice). Unpaired $t$-test, ${ }^{*} P<0.01$ 

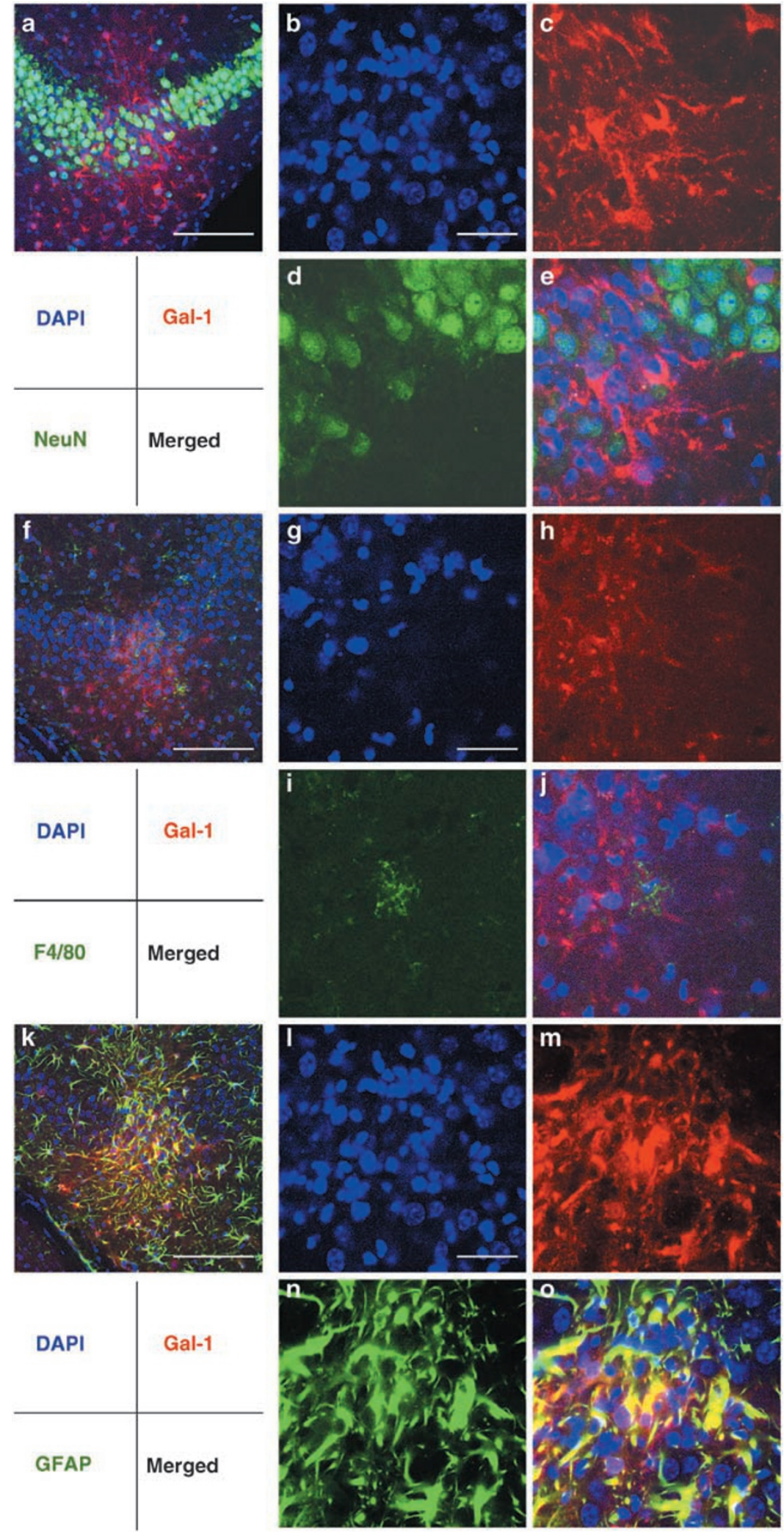

Figure 2 Kainate administration induces the expression of galectin-1 in activated astrocytes in the CA3 subregion of mouse hippocampus. Mouse brain sections were prepared a week after kainate administration, and were subjected to multi-immunofluorescence microscopy with a laser scanning confocal microscope. (a-e) Expression of galectin-1 in neurons. Blue, DAPI; red, galectin-1 (Gal-1); and green, NeuN. (f-j) Expression of galectin-1 in microglias. Blue, DAPI; red, galectin-1 (Gal-1); green, F4/80. (k-0) Expression of galectin-1 in astrocytes. Blue, DAPI; red, galectin-1 (Gal-1); and green, GFAP. Scale bars: a, $\mathbf{f}$ and $\mathbf{k}, 200 \mu \mathrm{m} ; \mathbf{b}-\mathbf{l}, \mathbf{g}-\mathbf{j}$ and $\mathbf{I}-\mathbf{0}, 50 \mu \mathrm{m}$ 
a
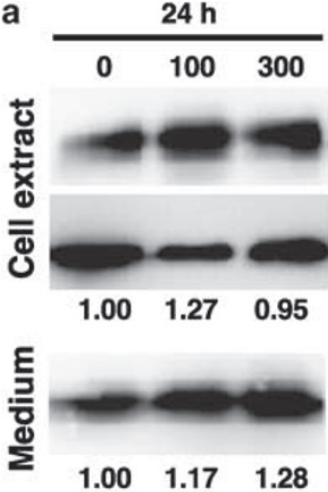
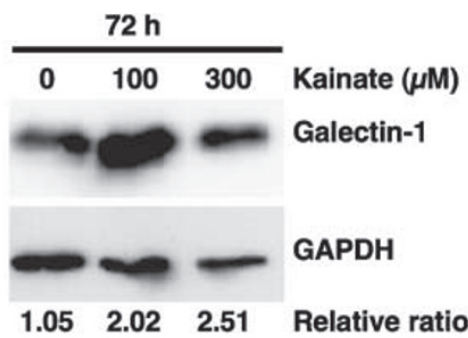

$\begin{array}{llll}1.05 & 2.02 & 2.51 & \text { Relative ratio }\end{array}$

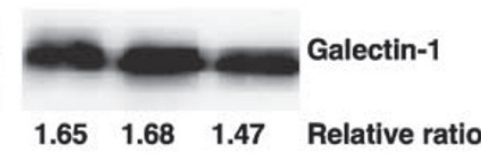

b
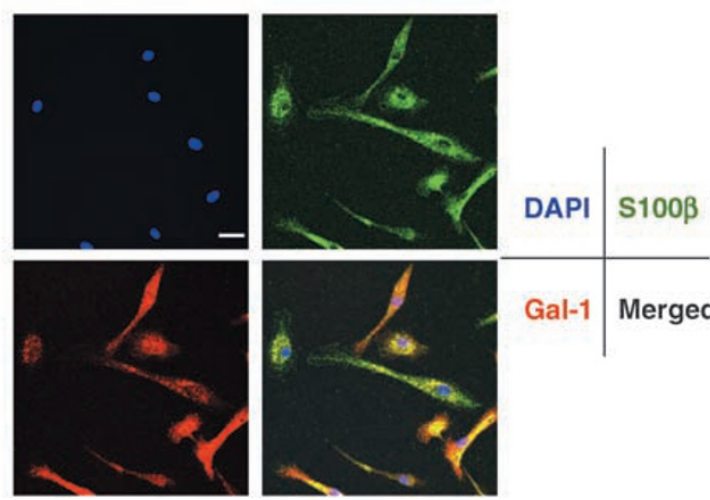

Gal-1 Merged

Figure 3 Isolated primary astrocytes express and secrete galectin-1 in vitro. (a) Astrocytes isolated from the cerebral cortex obtained from neonatal C57BL/6J mice were kept in a serum-free medium containing 0,100 , and $300 \mu \mathrm{M}$ kainate for 24 or $72 \mathrm{~h}$. After exposure to kainate, cell extracts from cultured astrocytes and conditioned media were collected and were subjected to western blotting using antirhGal-1. Upper panel: galectin-1 from cell extracts, middle panel: GAPDH from cell extracts, lower panel: galectin-1 in conditioned media. The amount of galectin-1 protein determined by western blotting was normalized with that of GAPDH. $(N=3$ per group). The amount of galectin-1 in conditioned media is indicated relative to that of the sample without kainate exposure at $24 \mathrm{~h}$ ( $N=3$ per group). (b) Galectin-1 expression in cultured astrocytes. Cultured astrocytes were subjected to immunofluorescence confocal microscopy with anti-rhGal-1 and anti-S100 $\beta$. Blue, DAPI; red, galectin-1 (Gal-1); and green, S100 $\beta$. Scale bar $=40 \mu \mathrm{m}$

stellate processes, especially in their soma and processes (Figure 1e, inset). Intensities of galectin-1 immunoreactivity in the CA3 subregion were increased about three-fold 1 week after kainate administration (Figure 1g).

To evaluate the level of galectin-1 mRNA in the hippocampus, we performed quantitative real-time reverse transcription PCR (RT-PCR). The relative expression level of galectin-1 mRNA began to increase 1 day after kainate administration, and peaked at a level that was 13-fold higher than that of the untreated group 3 days after the exposure (Figure 1h). A 14.5$\mathrm{kDa}$ galectin-1 protein, which exhibited the same mobility as the recombinant mouse galectin-1 protein, was detected in wild-type but not in galectin-1 knockout mice samples, and the level of galectin-1 protein reached a three-fold higher level 1 week after the exposure, as compared with the level seen in the untreated group (Figure 1i). We thus concluded that the systemic administration of kainate resulted in an increase in galectin-1 gene expression and the accumulation of galectin-1 protein in the adult mouse hippocampus.
Systemic administration of kainate induces the expression of galectin-1 in activated astrocytes in the CA3 subregion of mouse hippocampus. After kainate administration, galectin-1 immunoreactivity in the CA3 subregion was not detected in either neuron-specific nuclear protein (NeuN)-positive pyramidal neurons (Figure $2 a-e)$ or microglia with F4/80 immunoreactivity, whose level reached a maximum at $12 \mathrm{~h}$ post-exposure and then gradually decreased over a 1-week period (Figure $2 \mathrm{f}-\mathrm{j}$ ). ${ }^{21}$ Instead, as shown in Figure $2 \mathrm{k}-0$, most galectin-1 immunoreactivity in the CA3 subregion after kainate administration co-localized with glial fibrillary acidic protein (GFAP) immunoreactivity. From these results, we concluded that the systemic administration of kainate induces a gliotic response, namely the proliferation of astrocytes in the CA3 subregion. Thereafter, the activated astrocytes produce a large quantity of galectin-1.

To confirm that galectin-1 is indeed expressed in astrocytes, as seen in the hippocampus after kainate administration, we isolated astrocytes from neonatal mouse brains and examined their expression of galectin-1. As shown in Figure 3a (upper panel: cell extract), a substantial amount of galectin-1 was detected in the cultured astrocytes in the absence of kainate, and the level was increased more than two-fold $72 \mathrm{~h}$ after exposure to kainate (100 and $300 \mu \mathrm{M})$. Furthermore, we detected galectin-1 in conditioned media prepared from cultures of astrocytes in the presence or absence of kainate (Figure 3a, lower panel: medium). The amount of galectin-1 in the conditioned medium was slightly increased $24 \mathrm{~h}$ after the kainate exposure. The viability of astrocytes was not decreased in the presence of kainate and there was no detectable GAPDH (glyceraldehyde-3-phosphate dehydrogenase) protein in the conditioned media (data not shown). We therefore concluded that cultured astrocytes express and secrete galectin-1.

As shown in Figure 3b, immunofluorescence confocal microscopy revealed that galectin-1 was localized in the nucleus as well as in the cytoplasm of cultured astrocytes in the absence of kainate and its localization was not altered with kainate exposure (data not shown).

Galectin-1 deficiency does not affect the degeneration of CA3 pyramidal neurons or gliosis in the hippocampus induced by kainate administration. After kainate exposure, wild-type and galectin-1 knockout mice exhibited an almost identical time course as that of epileptiform seizure, and although the extent of the seizure was slightly lower in the galectin-1 knockout mice, this difference was not statistically significant (Figure 4a). Furthermore, the two groups of mice exhibited the same survival rate $(100 \%)$ at 1 week after kainate administration. NeuN immunoreactivity in the CA3 subregion was not decreased in either wild-type or galectin-1 knockout mice (Figure $4 \mathrm{~b}-\mathrm{e}$ and j), indicating no apparent neuronal loss in the CA3 subregion. The mouse 129 strain used in this experiment is known to respond mildly to kainate as compared with other mouse strains, ${ }^{22}$ and this may be the reason why we did not observe a loss of pyramidal cells in CA3. The extent of gliosis in the CA3 subregion was assessed by GFAP immunoreactivity, and we found that, after kainate administration, the GFAP index in 
galectin-1 knockout mice was slightly lower than that in the wild-type mice; however, the difference between the two groups was not significant (Figure $4 f-i$ and $k$ ). We thus concluded that the increased expression of galectin-1 in the hippocampus did not contribute to either the degeneration of the CA3 pyramidal neurons or to gliosis induced by the systemic administration of kainate.

Systemic administration of kainate also induces the expression of galectin-1 in the dentate gyrus and hippocampal hilus. Recently, it has been reported that
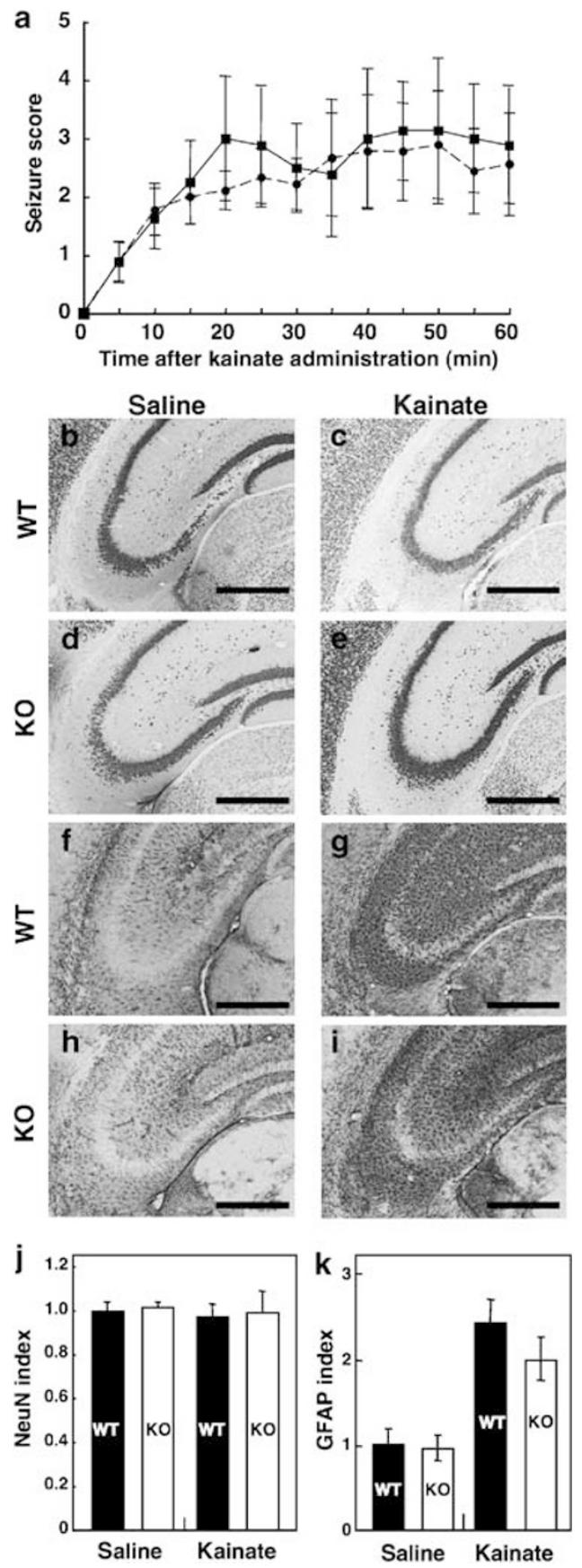

galectin-1 is expressed in a subset of slowly dividing astrocytes in the subventricular zone (SVZ) of the lateral ventricle, including neural stem cells, ${ }^{23}$ and it is also known that kainate-induced seizure is accompanied by enhanced neurogenesis in the subgranular zone (SGZ) of the dentate gyrus in the hippocampus. ${ }^{5}$ We therefore hypothesized that the increased expression of galectin-1 after kainate administration may modulate the extent of neurogenesis in the dentate gyrus. To evaluate this hypothesis, we then examined the alteration of galectin-1 expression in this region, as well as the extent of proliferation of neural progenitors, after the systemic administration of kainate.

Mice were injected intraperitoneally with either saline (vehicle) or $30 \mathrm{mg} / \mathrm{kg}$ kainate and were then injected with $50 \mathrm{mg} / \mathrm{kg}$ 5-bromo-2'-deoxyuridine (BrdU) once a day for a week. The brain sections were examined under immunofluorescence confocal microscopy to detect BrdU, polysialylated neural cell adhesion molecule (PSA-NCAM) as a marker for young immature neurons, ${ }^{3}$ and $\mathrm{NeuN}$ as a neural marker together with galectin-1 (Figure 5). In the untreated brains, the expression of galectin-1 was barely detectable in the dentate gyrus, whereas scattered cells with large soma in the hippocampal hilus exhibited a low but measurable level of galectin-1 expression (Figure $5 \mathrm{~b}, \mathrm{j}$ and $\mathrm{r}$ ). After kainate administration, the expression level of galectin-1 was greatly increased, especially in the SGZ of the dentate gyrus (Figure $5 f, n$ and $v$ ). The BrdU-positive population was significantly increased after kainate administration, as shown later in Figure 7, but most of BrdU-positive cells did not exhibit galectin-1 immunoreactivity (Figure 5e-h). However, it was noteworthy that we infrequently observed co-localization of galectin-1 immunoreactivity in a small population of BrdUpositive cells (Figure 5e-h; 5.53\% arrowhead). PSA-NCAMpositive cells whose population was also significantly increased after kainate administration did not exhibit galectin-1 immunoreactivity (Figure $5 \mathrm{~m}-\mathrm{p}$ ). Cells expressing doublecortin (DCX), another marker for young immature neurons, ${ }^{3}$ were found in the SGZ after the exposure to kainate, and these

Figure 4 Galectin-1 deficiency does not affect kainate-induced degeneration of CA3 pyramidal cells or the proliferation of astrocytes in the hippocampus. (a) Seizure responses after kainate administration. Every $5 \mathrm{~min}$ for $1 \mathrm{~h}$ after kainate administration, the observed seizures were scored as described in Materials and Methods, and the mean \pm SD value at each time point was plotted. Eight to nine mice per group were observed and scored. Square, wild-type mice; circle, galectin-1 knockout mice. (b-e) The mice were killed 1 week after kainate administration (kainate) or after saline injection (saline), and brain sections were prepared for NeuN immunohistochemistry. $(\mathbf{f}-\mathbf{i})$ Gliosis in the mouse hippocampus after kainate administration. Wild-type (WT) and galectin-1 knockout mice (KO) were injected with kainate (kainate) or saline (saline), and at 1 week after the injection, brains were removed and coronal sections were subjected to IHC with anti-GFAP antibody. (j) Galectin-1 deficiency does not affect neurodegeneration in the CA3 subregion after kainate administration. Each NeuN index relative to the value of the untreated group (saline) is shown as a bar graph with the mean \pm SD (saline-injected mice, $N=3$; kainate-injected mice, $N=3$ ). There was no statistically significant difference between the wild-type (WT) and galectin-1 knockout mice (KO) (examined by the unpaired $t$-test). (k) Galectin-1 deficiency does not affect gliosis in the hippocampus after kainate administration. Each GFAP index relative to the value of the untreated group (saline) is shown as a bar graph with the mean \pm SD (saline-injected mice, $N=5$; kainate-injected mice, $N=6$ ). There was no statistically significant difference between the wild-type (WT) and galectin-1 knockout mice (KO) (examined by the Mann-Whitney U-test). Scale bars $=500 \mu \mathrm{m}$ 

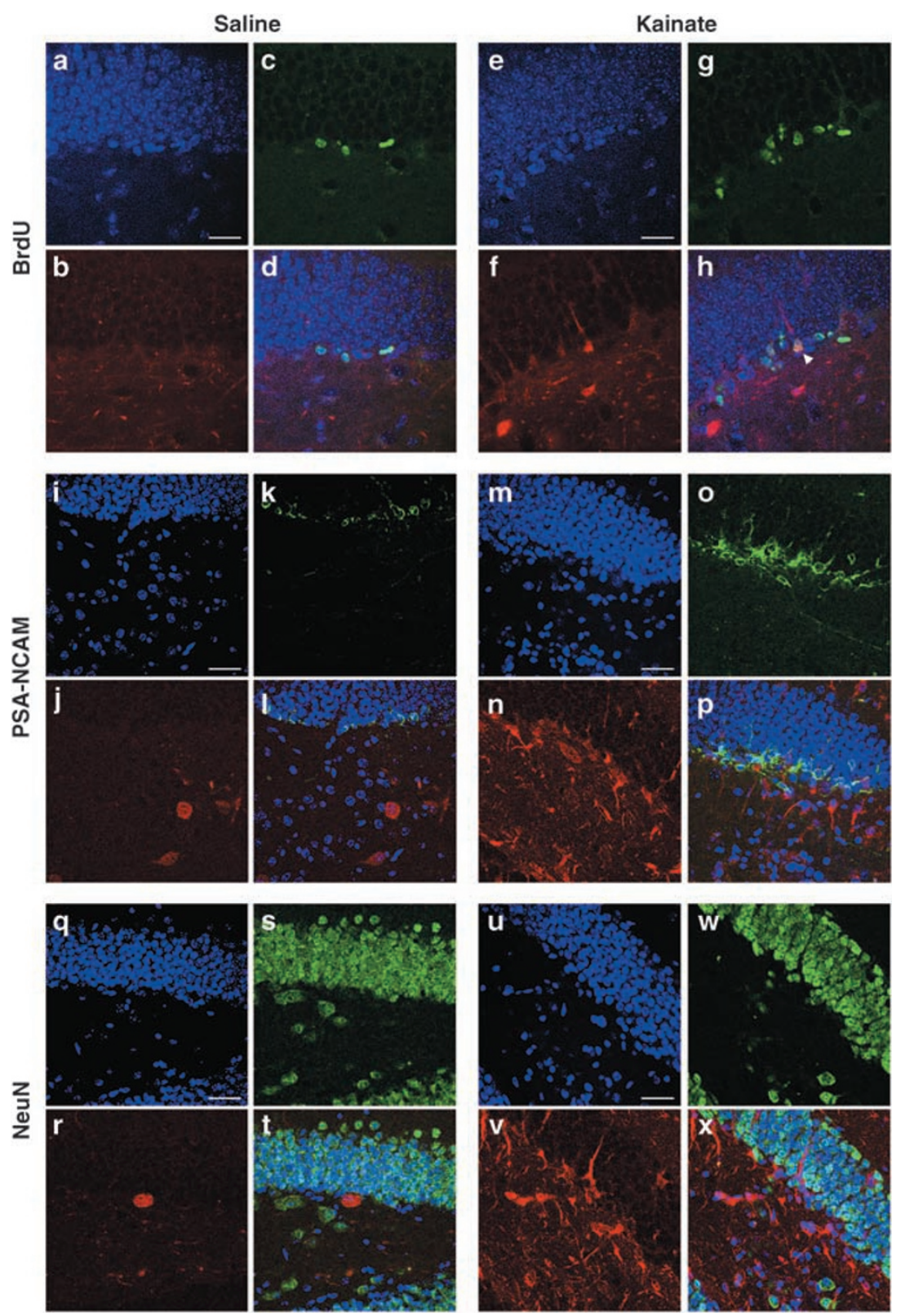

Figure 5 Kainate-induced cell proliferation in the dentate gyrus accompanied by the increased expression of galectin-1. After kainate administration (kainate), the mice were injected with BrdU once a day for 1 week, then brain sections were prepared and subjected to IHC. Untreated mice (saline) were injected with saline instead of kainate. (a-h) Cell proliferation and expression of galectin-1 in the dentate gyrus after kainate administration. DAPI (a, e; blue), galectin-1 (b, $\mathbf{f}$; red), BrdU (c, $\mathbf{g}$; green), and their merged images are shown (d, $\mathbf{h})$. Out of 235 BrdU-positive cells, 13 cells $(5.53 \%)$ exhibited galectin-1 immunoreactivity as shown by an arrowhead (h). (i-p) Distribution of newborn neurons and expression of galectin-1 in the dentate gyrus after kainate administration. DAPI (i, $\mathbf{m} ;$ blue), galectin-1 (j, $\mathbf{n}$; red), PSA-NCAM (k, $\mathbf{0}$; green), and their merged images are shown (I, p). (q-x) Distribution of NeuN-positive cells and the expression of galectin-1 in the dentate gyrus after kainate administration. DAPI (q, $\mathbf{u}$; blue), galectin-1 (r, v; red), NeuN (s, w; green), and their merged images are shown (t, $\mathbf{x})$. Scale bars $=50 \mu \mathrm{m}$

were also mostly galectin-1-negative (Supplementary Figure S2). Furthermore, almost all NeuN-positive neurons were galectin-1-negative regardless of whether kainate was administered (Figure $5 \mathrm{q}-\mathrm{x}$ ).

To identify cells expressing galectin- 1 in the dentate gyrus and hilus of the hippocampus, we next performed immunofluorescence confocal microscopy with antibodies against GFAP, $\mathrm{S} 100 \beta$, or nestin together with the antibody against galectin-1 (Figure 6). GFAP-positive cells in the dentate gyrus and hilus of the hippocampus expressed an increased level of galectin-1 after the kainate exposure, as was seen in the CA3 subregion, and some of the galectin-1/GFAP double-positive cells in the SGZ extended their processes into the granular cell layer (GCL) (Figure 6a-h). On the other hand, $\mathrm{S} 100 \beta$ positive astrocytes mostly distributed in the hilus also showed an increased expression of galectin-1 after the kainate exposure, and galectin-1-positive cells in the SGZ were mostly $\mathrm{S} 100 \beta$-negative (Figure 6i-p). In addition, most 

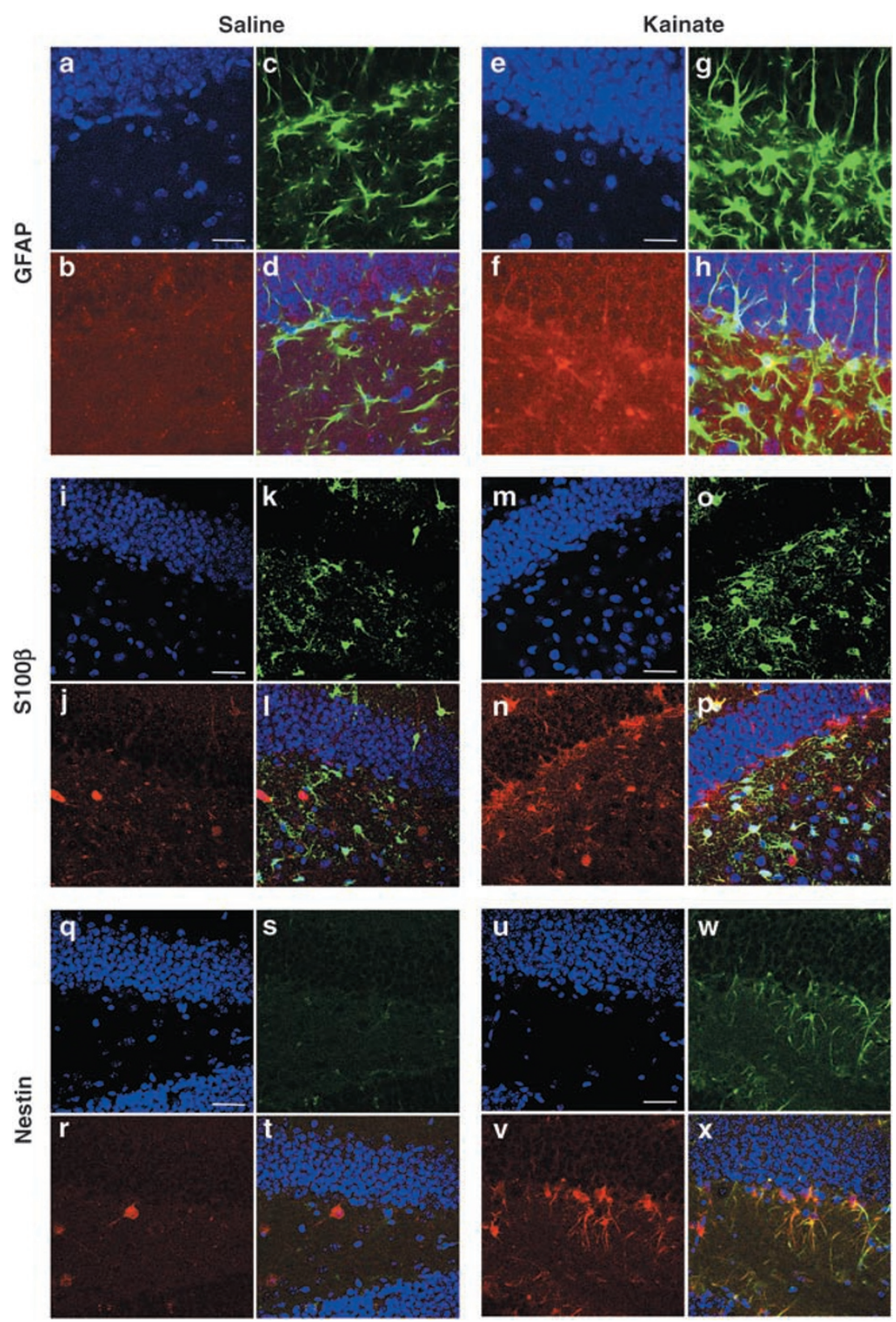

Figure 6 Galectin-1 is expressed in neural progenitors and astrocytes in the dentate gyrus after kainate-induced seizure. (a-h) Distribution of GFAP-positive cells and the expression of galectin-1 in the dentate gyrus after kainate administration. DAPI (a, e; blue), galectin-1 (b, f; red), GFAP (c, g; green), and their merged images are shown (d, h). (i-p) Distribution of $\mathbf{S} 100 \beta$-positive cells and expression of galectin-1 in the dentate gyrus after kainate administration. DAPI (i, $\mathbf{m} ;$ blue), galectin-1 (j, n; red), S100 $\beta$ (k, $\mathbf{0}$; green), and their merged images are shown (I, $\mathbf{p})$. (q-x) Distribution of nestin-positive cells and the expression of galectin-1 in the dentate gyrus after kainate administration. $\operatorname{DAPI}(\mathbf{q}, \mathbf{u}$; blue), galectin-1 (r, $\mathbf{v}$; red), nestin (s, w; green), and their merged images are shown (t, $\mathbf{w})$. Scale bars $=50 \mu \mathrm{m}$

nestin-positive cells representing neural progenitors in the $S G Z,{ }^{3}$ which appeared after the kainate exposure, were found to express galectin-1 (Figure 6q-x).

Galectin-1 deficiency attenuates both of basal and of kainate-induced proliferation of neural progenitors in the adult mouse hippocampus. In order to clarify the role of galectin-1 in kainate-induced neurogenesis in the dentate gyrus, we compared numbers of BurU-positive cells in the dentate GCL of wild-type and galectin-1 knockout mice administered saline or kainate. Counts were obtained using unbiased stereological counting techniques. In control groups administered saline, the density of BrdU-positive cells in the GCL of galectin-1 knockout mice (mean $\pm \mathrm{SD}=7560 \pm 825$ cells per $\mathrm{mm}^{3}$ ) was $62 \%$ of that seen in the wild-type mice $\left(12222 \pm 2833\right.$ cells per $\left.\mathrm{mm}^{3}\right)$ $(P<0.05)$ (Figure $7 \mathrm{a}, \mathrm{b}$ and $\mathrm{e})$. Furthermore, the numbers of BrdU-positive cells in the GCL of both wild-type and galectin1 knockout mice were remarkably increased 1 week after kainate administration (Figure 7c and d), and the density of these cells in the GCL of galectin-1 knockout mice (19185 \pm 5624 cells per $\mathrm{mm}^{2}$ ) was again $52 \%$ of that seen 


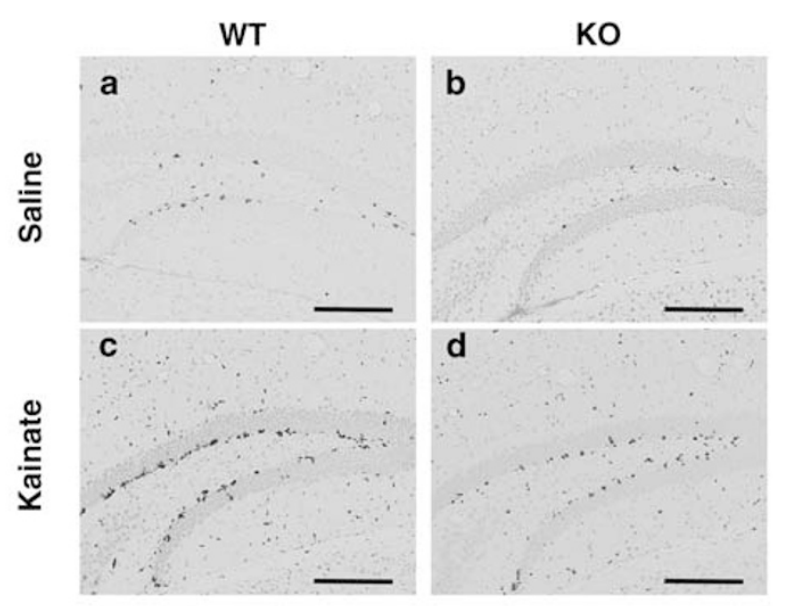

e

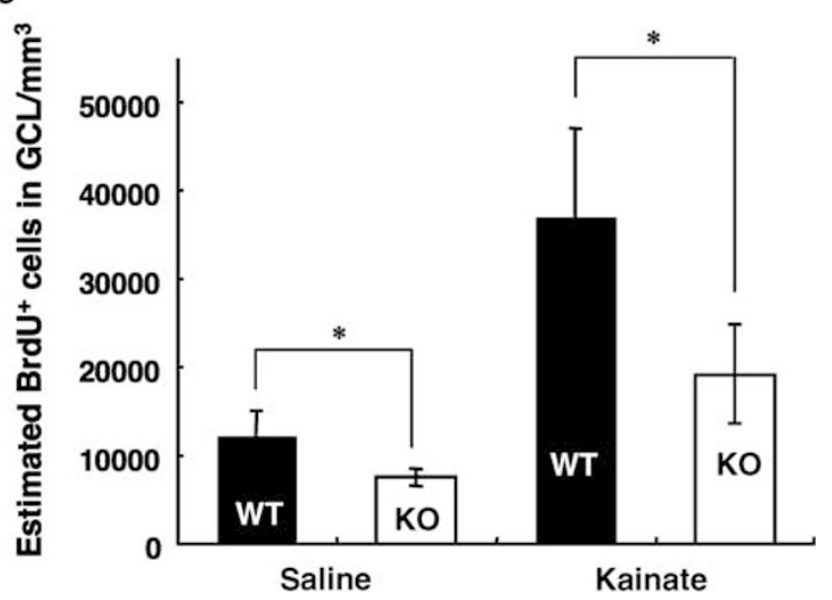

Figure 7 Galectin-1 deficiency attenuates both of basal and kainate-induced proliferation of neural progenitors in the dentate gyrus. After kainate administration (kainate), the mice were injected with BrdU once a day for 1 week, then brain sections were prepared and subjected to $\mathrm{IHC}$ to detect BrdU-positive cells. Untreated mice (saline) were injected with saline instead of kainate. (a-d) Detection of BrdU-positive cells in the mouse hippocampus with or without kainate administration. (e) Galectin-1 knockout mice exhibited a significant reduction in the number of BrdU-positive cells in the hippocampal GCL with or without kainate administration. Brain sections from each group $(N=5)$ were prepared and subjected to $\mathrm{IHC}$ to detect BrdU-positive cells in this region. The density of BrdUpositive cells in the hippocampal GCL was determined stereologically (cells per $\mathrm{mm}^{3}$ ), and is shown in the bar graph with the mean $\pm \mathrm{SD}$. Black bar, wild-type mice; white bar, galectin-1 knockout mice. Mann-Whitney $U$-test, ${ }^{*} P<0.05$. Scale bars $=500 \mu \mathrm{m}$

in wild-type mice $\left(36952 \pm 9979\right.$ cells per $\left.\mathrm{mm}^{2}\right)(P<0.05)$ (Figure 7e). In galectin-1 knockout mice, the kainate-induced increase in the density of BrdU-positive cells (mean increase $=11625$ cells per $\mathrm{mm}^{3}$ ) was about $47 \%$ of that seen in the wild-type mice (mean increase $=24730$ cells per $\mathrm{mm}^{3}$ ). There was no significant difference in the volume of the dentate GCL between the two mouse strains with or without kainate administration (data not shown).

We finally performed immunofluorescence confocal microscopy to confirm that the BrdU-positive cells in the dentate SGZ express DCX or NeuN (Supplementary Figure S3), and found that more than $70 \%$ of the BrdU-positive cells were DCX-positive both in wild-type and galectin-1 knockout mice regardless of kainate administration. Furthermore, $70-80 \%$ of the BrdU-positive cells were also NeuN-positive both in wild-type and in galectin-1 knockout mice. About half of DCX-positive cells in the SGZ express lower levels of NeuN in comparison to NeuN-positive neurons in GCL (Supplementary Figure S4), indicating that they are young immature neurons. We thus concluded that galectin-1 deficiency significantly attenuates proliferation of neural progenitors in the dentate gyrus of the adult mouse hippocampus both in the presence and absence of brain insult.

\section{Discussion}

In this study, we found for the first time that the expression of the galectin-1 gene, both at mRNA and protein levels, is highly induced in activated astrocytes in the CA3 subregion and the dentate gyrus of the adult mouse hippocampus after epileptic seizure caused by the systemic administration of kainate. Furthermore, we showed that galectin-1 deficiency results in attenuated proliferation of neural progenitors in the dentate gyrus both in the presence and absence of brain insult, showing that galectin-1 enhances proliferation of neural progenitors in the adult mouse hippocampus.

Recently, Sakaguchi et al. ${ }^{23}$ reported that neural stem cells in the SVZ express galectin-1, and that the population of BrdU-positive cells in the SVZ of galectin-1 knockout mice was $50 \%$ of that seen in the wild-type mice. Furthermore, they showed that recombinant galectin-1 promoted the proliferation of neural stem cells both in vitro and in vivo. In this study, we found that a substantial level of galectin-1 is expressed in the hippocampus of normal mice (Figure 1), and that the density of BrdU-positive cells in the dentate GCL of galectin-1 knockout mice was $62 \%$ of that seen in the wild-type mice (Figure 7). As more than $70 \%$ of BrdU-positive cells in the GCL of both mouse strains were either DCX- or NeuNpositive, markers for newborn neurons or neural cells, respectively ${ }^{3}$ (Supplementary Figure S3), our results indicate that galectin-1 may promote basal neurogenesis in the GCL as well as in the SVZ under normal conditions.

The level of galectin-1 mRNA in the hippocampus began to increase within 1 day of kainate administration and reached a peak within 3 days, followed by an increased expression of galectin-1 protein in the CA3 subregion and the dentate gyrus of the hippocampus 1 week after the exposure (Figure 1). Immunofluorescence confocal microscopy revealed that activated astrocytes in the CA3 subregion and the dentate gyrus as well as neural progenitors in the SGZ of the dentate gyrus had a significantly increased expression of galectin-1 after exposure to kainate (Figures 2 and 6). We isolated astrocytes from neonatal mouse brains, and showed that astrocytes do indeed express and secrete galectin-1 in culture, and that this expression was increased in the presence of kainate (Figure 3). Adult neurogenesis in either the SGZ or SVZ is reported to be enhanced after insult to the brain. ${ }^{5,13,24-26}$ After kainate was administered to wild-type mice, the density of BrdU-positive cells in the GCL increase significantly (mean increase $=24730$ cells per $\mathrm{mm}^{3}$ ); however, after it was administered to galectin-1 knockout mice, a lower increase in the density (mean increase $=11625$ cells per $\mathrm{mm}^{3}$ ) was observed. Again, more than $70 \%$ of 
BrdU-positive cells in both mouse strains were either DCX- or NeuN-positive, indicating that galectin-1 also promotes insultinduced proliferation of neural progenitors in the dentate gyrus. We thus concluded that galectin-1 expressed in activated astrocytes may be involved in the promotion of insult-induced neurogenesis in the dentate gyrus. Recently, it has been reported that a lack of galectin-1 results in defects in myoblast fusion and muscle regeneration after cardiotoxin injury. ${ }^{27}$ Taken together, we may suggest that galectin- 1 plays an important role during tissue regeneration in response to insults in general.

It is known that astrocytes promote neurogenesis in the adult hippocampus, ${ }^{28}$ and we showed in this study that when the hippocampus underwent kainate-induced seizure, activated astrocytes predominantly expressed galectin-1 not only in the CA3 subregion but also in the dentate gyrus, where seizure-induced neurogenesis takes place. Furthermore, in the dentate gyrus, galectin-1 is expressed in GFAP- or nestinpositive but PSA-NCAM/NeuN/BrdU-negative cells, which are likely to be slowly dividing neural progenitors. ${ }^{3,29,30}$ As shown in Figure $5 \mathrm{e}-\mathrm{h}$, we infrequently observed co-localization of galectin-1 immunoreactivity in a small population of BrdUpositive cells after kainate administration, which may represent the slowly dividing neural progenitors. Taken together, we propose that, after kainate-induced seizure, activated astrocytes and neural progenitors produce and secrete galectin-1 and that the secreted galectin-1 promotes proliferation or survival of the latter cells, thus enhancing neurogenesis in the dentate gyrus (Figure 8).

It is most likely that the galectin-1 secreted from the activated astrocytes functions as a growth-stimulating or survival factor for neural stem cells or progenitors as astrocytes are known to constitute a niche for these types of cells. Galectin-1 is a multifunctional molecule, but the mechanisms for how galectin1 functions in the central nervous system are not yet well known. It has been reported that galectin- 1 induces brain derived neurotrophic factor (BDNF) in astrocytes. ${ }^{31}$ Furthermore, it was also reported that BDNF promotes adult neurogenesis. ${ }^{3,32}$ Astrocytes expressing galectin-1 may thus increase the supply of such neurotrophic factors to promote neurogenesis after brain insults.

Axonal regeneration after axotomy of the peripheral nerves is known to be significantly promoted by an oxidized monomeric form of galectin-1 but not by the natural dimeric form. ${ }^{20,33}$ It has been shown that oxidized galectin-1 acts directly on macrophages, which in turn may produce a factor that promotes axonal growth. ${ }^{33}$ We have shown earlier that exposure to kainate significantly increases oxidative stress in the hippocampus and that oxidative damage of cellular components is accumulated in hippocampal neurons, astrocytes, and microglias. ${ }^{21}$ Therefore, we suggest that astrocytesecreted galectin-1, which is likely to be mostly oxidized, may function in promoting neurogenesis in the dentate gyrus. Identification of the receptor(s) and interacting molecules on these cells would shed light on the network used to regulate insult-induced neurogenesis.

\section{Materials and Methods}

Antibodies. Mouse monoclonal antibody to BrdU (BMC9318, 1:800) was obtained from Roche Diagnostics Japan (Tokyo, Japan). Rat monoclonal antibody

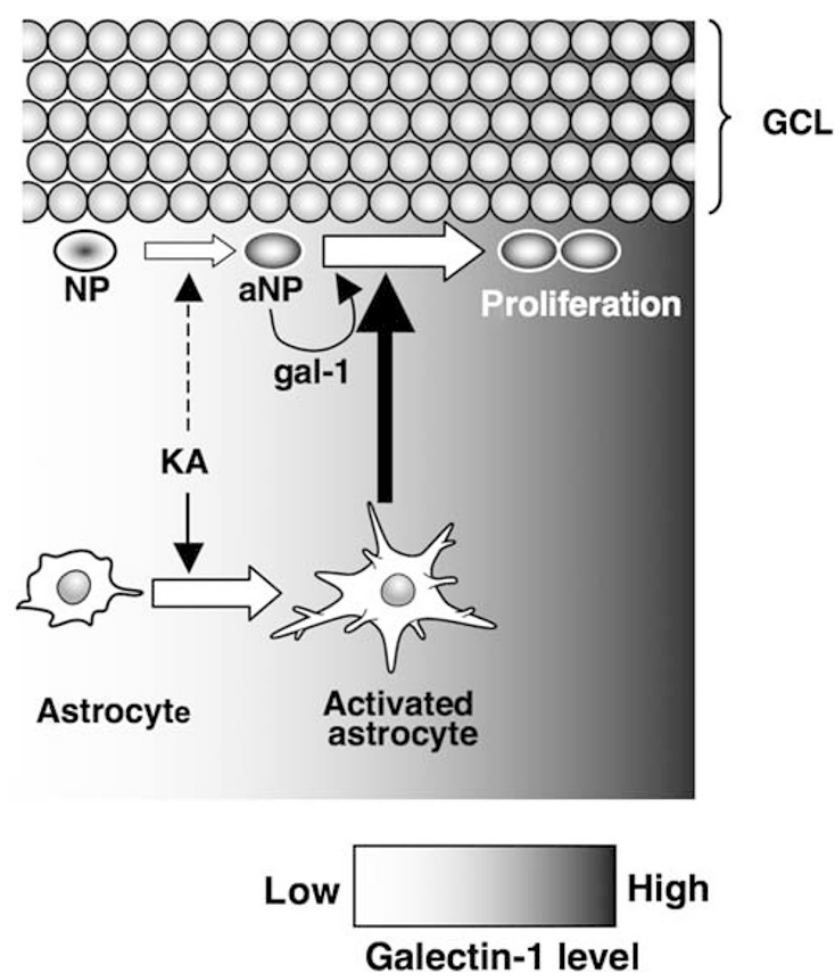

Figure 8 The role of galectin-1 in insult-induced neurogenesis in the dentate gyrus. Kainate administration activates astrocytes and neural progenitors, which results in an increased secretion of galectin-1 in the hippocampal formation. The secreted galectin-1 promotes the proliferation or survival of neural progenitors in the SGZ of dentate gyrus, thereby promoting neurogenesis. The gradient shown at the bottom indicates the level of galectin-1 protein in the niche. Gal-1, galectin-1; KA, kainate; NP, neural progenitor; aNP, activated neural progenitor; GCL, granule cell layer

to BrdU (BU1/75 (ICR1) 1: 1000) was obtained from Abcam KK (Tokyo, Japan). The rabbit polyclonal antibodies (anti-rhGal-1) against recombinant human galectin1 have been described earlier. ${ }^{20}$ Mouse monoclonal antibody to GFAP (G-A-5, $1: 15000$ ), a marker for astrocytes, and mouse monoclonal antibody to $\mathrm{S} 100 \beta$ (SH$B 1,1: 1000)$, which is a specific marker for astrocytes, were purchased from SigmaAldrich Japan KK (Tokyo, Japan). Rat monoclonal antibody to F4/80 (Cl:A3-1, 1:500), a marker for microglia, was purchased from SEROTEC (Oxford, UK). Mouse monoclonal antibody to NeuN (A60, 1:30000), a marker for mature neurons, and mouse monoclonal antibody to PSA-NCAM (2-2B, 1:800) were purchased from Chemicon (Temecula, CA, USA). Mouse monoclonal antibody to nestin (rat401, 1: 400) was purchased from BD Bioscience Pharmingen (San Jose, CA, USA). Goat polyclonal antibody to DCX was purchased from Santa Cruz Technology (Santa Cruz, CA, USA). Alexa Fluor-labeled second antibodies were obtained from Invitrogen Japan (Tokyo, Japan).

Animals. For the analysis of galectin-1 expression by IHC, RT-PCR and western blotting, we used C57BL/6J mice (Clea Japan Inc., Tokyo, Japan). Galectin-1 knockout (129 P3/J Lgals ${ }^{-1-}$ ) and wild-type mice (129 P3/J Lgals ${ }^{+1+}$ ), described earlier, ${ }^{34}$ were used to compare seizure responses, gliosis, and neurogenesis after kainate administration. All animals were maintained in an airconditioned specific pathogen-free room with a time-controlled lighting system. The handling and killing of all animals were carried out in accordance with nationally prescribed guidelines, and ethical approval for the study was granted by the Animal Care and Use Committee (Kyushu University, Fukuoka, Japan).

Experimental design and kainate treatment. Eight- to 10-week-old male mice were used for this study. The mice were injected intraperitoneally with either saline (vehicle) or $30 \mathrm{mg} / \mathrm{kg}$ kainate (Wako, Osaka, Japan) dissolved in saline, 
and were then injected daily for 1 week with $50 \mathrm{mg} / \mathrm{kg}$ BrdU (Sigma-Aldrich Japan KK, Tokyo, Japan) dissolved in saline. To compare the degree of epileptiform seizure, we observed mice for $1 \mathrm{~h}$ after kainate administration and recorded the seizure score: 0 , no reaction; 1 , arrest of motion; 2 , myoclonic jerks of the head and neck, with brief twitching movements; 3 , unilateral clonic activity; 4 , bilateral forelimb tonic and clonic activity; and 5 , generalized tonic-clonic activity with loss of postural tone as well as death from continuous convulsion, according to previously described criteria. ${ }^{21,35}$ Animals were killed 1 day after the last BrdU injection, unless otherwise noted.

Tissue processing and IHC. The animals were deeply anesthetized with pentobarbital (30 mg/kg, i.p.) and were perfused intracardially with saline followed by cold $4 \%$ paraformaldehyde in $0.1 \mathrm{M}$ PBS. The brains were removed, immersed for $12 \mathrm{~h}$ in the same $4 \%$ paraformaldehyde fixative at $4{ }^{\circ} \mathrm{C}$, and cryoprotected in 20 and $30 \%$ sucrose in PBS for $48 \mathrm{~h}$ at $4{ }^{\circ} \mathrm{C}$. The brains were then frozen and stored at $-80{ }^{\circ} \mathrm{C}$ until use. Serial coronal sections ( $40 \mu \mathrm{m}$ thickness) were cut on a cryostat, collected as free-floating sections ( $40 \mu \mathrm{m}$ thickness) in PBS, and then were processed immediately for $\mathrm{IHC}$, according to previously described methods. ${ }^{21}$ Digital images were acquired using Axioskop2 Plus equipped with a CCD camera, AxioCam (Carl Zeiss Microlmaging Japan, Tokyo, Japan).

Quantitative analysis of galectin-1 and NeuN expression in the hippocampus. Galectin-1 and NeuN immunostaining was performed with four representative coronal sections from each brain sample. All acquired digital images were processed uniformly at a threshold in gray-scale mode to subtract any background corresponding to areas without tissue, using Adobe Photoshop version 7.0 (Adobe Systems, San Jose, CA, USA). The intensity of each immunoreactivity in a given area of hippocampus (CA3 subregion) was measured using Image Gauge version 3.2 (Fujifilm, Tokyo, Japan). Representative coronal sections were measured and the mean intensity of each immunoreactivity was calculated for each animal as the galectin-1 or NeuN index in CA3.

Quantitative analysis of gliosis by immunohistochemical detection. GFAP immunostaining was performed with six coronal sections from each brain sample corresponding to each first section of six serial sections (bregma -2.54 to $-1.70 \mathrm{~mm}$ ). ${ }^{36}$ All acquired digital images were processed uniformly at a threshold in gray-scale mode to subtract any background corresponding to the area without tissue, using Adobe Photoshop version 7.0. The intensity of GFAP immunoreactivity in any given area of the CA3 subregions was measured using Image Gauge version 3.2. Six representative coronal sections with two hippocampus formations corresponding to each first section of six seria sections (bregma -2.54 to $-1.70 \mathrm{~mm}$ ) were measured and the mean intensity of GFAP immunoreactivity was calculated as the GFAP index for each individual animal.

Counting BrdU-positive cells using unbiased stereological counting techniques. Free-floating sections were incubated in $70 \%$ formamide in $2 \times \mathrm{SSC}$ for $2 \mathrm{~h}$ at $65^{\circ} \mathrm{C}$. The sections were washed in PBD (Triton $\mathrm{X}-100,0.3 \%$ in PBS) and immersed in $\mathrm{H}_{2} \mathrm{O}$ for $10 \mathrm{~min}$. In addition, the sections were treated with $2 \mathrm{~N} \mathrm{HCl}$ at room temperature for $30 \mathrm{~min}$, thereby denaturing the nuclear DNA, and were then treated with Tris- $\mathrm{HCl}(\mathrm{pH} 7.5)$ for 10 min and subjected to IHC with the anti-BrdU antibody. The numbers of BrdU-positive cells in the dentate GCL and in corresponding sample volumes were determined in nine coronal sections, $120 \mu \mathrm{m}$ apart (bregma -2.46 to $-1.34 \mathrm{~mm}$ ), ${ }^{36}$ using a semiautomatic stereology system (Stereolnvestigator, MBF Bioscience, Williston, VT, USA). Cells that met the counting criteria through a 40- $\mu \mathrm{m}$ axial distance were counted according to the optical dissector principle. ${ }^{37}$ The GCL reference volume was determined by summing the traced granule cell area for each section multiplied by the distance between sections sampled.

Immunofluorescence confocal microscopy. Free-floating sections incubated with an appropriate primary antibody were then incubated with an Alexa Fluor-labeled second antibody for $45 \mathrm{~min}$ at room temperature. The sections were further incubated in a solution containing $0.05 \mu \mathrm{g} / \mathrm{ml}$ DAPI (Sigma-Aldrich Japan KK) for 10 min at room temperature, and mounted on slides with Vectashield (Vector Laboratories, Burlingame, CA, USA). Confocal images were acquired using Eclipse TE300 (Nikon, Kanagawa, Japan) equipped with the Radiance 2100 laserscanning confocal microscope system (Bio-Rad Laboratories, Hercules, CA, USA) or an LSM510 META Confocal Microscope System (Carl Zeiss Microlmaging
Japan). All sections from each experimental animal and the groups to be compared were processed in parallel.

Real-time RT-PCR analysis. Total RNA from the hippocampus of C57BL/6J mice was prepared using ISOGEN (Nippongene, Tokyo, Japan), and the obtained RNA was treated with RNase-free DNase, according to the manufacturer's instructions. RT-PCR for galectin-1 and GAPDH mRNAs was performed as follows. First-strand cDNA, which was synthesized using a High Capacity cDNA Reverse Transcription Kit (Applied Biosystems Japan, Tokyo, Japan) according to the manufacturer's instructions, was subjected to real-time PCR. RT-PCR and the detection of the PCR product in real time were performed using with a POWER SYBR ${ }^{\circledR}$ GREEN PCR MASTER MIX and an ABI PRISM 7000 Sequence Detection System (Applied Biosystems Japan). Serially diluted CDNA was used to obtain a standard curve for each transcript. Primers for galectin-1 mRNA (gal1-F: CCTGGTCCATCTTCACTTCCAT; gal1-R: CTTTGGCCTGGAAAGCACAA) were obtained from Sigma-Aldrich Japan KK, and those for GAPDH mRNA (gapdh-F: AAATGGTGAAGGTCGGTGTG; gapdh-R: TGAAGGGGTCGTTGATGG) were obtained from TAKARA BIO (Shiga, Japan).

Western blotting. Mouse hippocampi were homogenized on ice in $200-400 \mu \mathrm{l}$ of lysis buffer containing $50 \mathrm{mM}$ Tris- $\mathrm{HCl}, \mathrm{pH} 8.0,150 \mathrm{mM} \mathrm{NaCl}, 0.5 \%$ sodium deoxycholate, $1 \%$ NP40, $0.1 \%$ SDS, and protease inhibitor cocktail (Nacala Tesque, Kyoto, Japan) using a Potter-type homogenizer. The lysates were centrifuged at $100000 \times g$ for $30 \mathrm{~min}$ and then the supernatants were recovered. Hippocampal lysates were subjected to SDS-PAGE (15\%) followed by western blotting using anti-rhGal-1 $(500 \mathrm{ng} / \mathrm{ml})$, according to a previously described method. ${ }^{38}$ Recombinant mouse galectin-1 (rmGal-1) expressed in Escherichia coli BL21 cells carrying pET8c: rmGal-1 was used as a standard. ${ }^{14}$ The amount of protein was measured using Image Gauge version 3.2.

Astrocyte culture. Primary astrocytes were prepared from the cerebral cortex of 1-day-old C57BL/6J mice, according to a method described earlier. ${ }^{39}$ Isolated astrocytes were maintained for 2 weeks in Dulbecco's modified Eagle's medium (Nissui, Tokyo, Japan) containing 10\% fetal calf serum (Hyclone, Logan, UT, USA), $0.5 \mu \mathrm{g} / \mathrm{ml}$ insulin (Nacalai Tesque, Kyoto, Japan), $2 \mathrm{mM}$ L-glutamine, $100 \mathrm{U} / \mathrm{ml}$ penicillin, $100 \mathrm{mg} / \mathrm{ml}$ streptomycin, and $0.2 \% \mathrm{NaHCO}_{3}$ at $37^{\circ} \mathrm{C}$ in $10 \% \mathrm{CO}_{2} / 90 \%$ air. The cell composition of the cultures was checked by immunostaining for $\mathrm{S} 100 \beta$, $\mathrm{NeuN}$, and Iba-1. Cultures containing more than $95-99 \%$ S100 $\beta$-positive cells were used (data not shown). Seeded astrocytes were kept in the serum-free medium with or without kainate for up to 2 days. After exposure to kainate, conditioned medium and astrocytes were collected and subjected to western blotting using anti-rhGal-1 $(500 \mathrm{ng} / \mathrm{ml})$, according to a previously described method. ${ }^{38}$ The conditioned medium was precipitated with trichloroacetic acid before western blotting.

Statistical analysis. The data are expressed as mean \pm SD. Relative IR comparison, western blotting analysis, real-time RT-PCR data, and NeuN index were compared using an unpaired $t$-test, and other data were compared using the Mann-Whitney U-test. A level of $P<0.05$ was considered statistically significant.

Acknowledgements. We are grateful to Dr. Kanba for providing us with the opportunity to conduct this study, and Dr. W Campbell for useful comments on this manuscript. We thank S Kitamura and A Matsuyama for their technical expertise. This work was supported by grants from the Ministry of Education, Culture, Sports, Science, and Technology of Japan and the Japan Society for the Promotion of Science (to $Y$ Nakabeppu); the 21st Century Centers of Excellence Program of MEXT (to Kyushu University); Kyushu University Interdisciplinary Programs in Education and Projects in Research Development (to K Kajitani); and Ligue Contre le Cancer, Comite de Paris, and Association Contre le Cancer (to F Poirier).

1. Morrison JH, Hof PR. Life and death of neurons in the aging brain. Science 1997; 278 : 412-419.

2. Meltzer LA, Yabaluri R, Deisseroth $\mathrm{K}$. A role for circuit homeostasis in adult neurogenesis Trends Neurosci 2005; 28: 653-660.

3. Zhao C, Deng W, Gage FH. Mechanisms and functional implications of adult neurogenesis. Cell 2008; 132: 645-660

4. Liu J, Solway K, Messing RO, Sharp FR. Increased neurogenesis in the dentate gyrus after transient global ischemia in gerbils. J Neurosci 1998; 18: 7768-7778. 
5. Gray WP, Sundstrom LE. Kainic acid increases the proliferation of granule cell progenitors in the dentate gyrus of the adult rat. Brain Res 1998; 790: 52-59.

6. Herdegen T, Leah JD. Inducible and constitutive transcription factors in the mammalian nervous system: control of gene expression by Jun, Fos and Krox, and CREB/ATF proteins. Brain Res Brain Res Rev 1998; 28: 370-490.

7. Nakabeppu Y, Ryder K, Nathans D. DNA binding activities of three murine Jun proteins: stimulation by Fos. Cell 1988; 55: 907-915.

8. Nakabeppu Y, Nathans D. A naturally occurring truncated form of FosB that inhibits Fos/ Jun transcriptional activity. Cell 1991; 64: 751-759.

9. Nakabeppu Y, Oda S, Sekiguchi M. Proliferative activation of quiescent Rat-1A cells by $\Delta$ FosB. Mol Cell Biol 1993; 13: 4157-4166.

10. Oda S, Nishida J, Nakabeppu Y, Sekiguchi M. Stabilization of cyclin E and cdk2 mRNAs at G1/ S transition in Rat-1A cells emerging from the G0 state. Oncogene 1995; 10: 1343-1351.

11. Nishioka T, Sakumi K, Miura T, Tahara K, Horie H, Kadoya T et al. FosB gene products trigge cell proliferation and morphological alteration with an increased expression of a nove processed form of galectin-1 in the rat 3Y1 embryo cell line. J Biochem 2002; 131: 653-661.

12. Tahara K, Tsuchimoto D, Tominaga Y, Asoh S, Ohta S, Kitagawa M et al. FosB, but not FosB, induces delayed apoptosis independent of cell proliferation in the Rat1a embryo cell line. Cell Death Differ 2003; 10: 496-507.

13. Kurushima H, Ohno M, Miura T, Nakamura TY, Horie H, Kadoya T et al. Selective induction of $\Delta$ FosB in the brain after transient forebrain ischemia accompanied by an increased expression of galectin-1, and the implication of $\Delta \mathrm{FosB}$ and galectin-1 in neuroprotection and neurogenesis. Cell Death Differ 2005; 12: 1078-1096.

14. Miura T, Takahashi M, Horie H, Kurushima H, Tsuchimoto D, Sakumi K et al. Galectin1beta, a natural monomeric form of galectin-1 lacking its six amino-terminal residues promotes axonal regeneration but not cell death. Cell Death Differ 2004; 11: 1076-1083.

15. Miura T, Ohnishi Y, Kurushima H, Horie H, Kadoya T, Nakabeppu Y. Regulation of the neuronal fate by DeltaFosB and its downstream target, galectin-1. Curr Drug Targets 2005; 6: 437-444.

16. Barondes SH, Cooper DN, Gitt MA, Leffler $\mathrm{H}$. Galectins. Structure and function of a large family of animal lectins. J Biol Chem 1994; 269: 20807-20810.

17. Hsu DK, Liu FT. Regulation of cellular homeostasis by galectins. Glycoconj J 2004; 19 : 507-515.

18. Scott K, Weinberg C. Galectin-1: a bifunctional regulator of cellular proliferation. Glycoconj J 2004; 19: 467-477.

19. Puche AC, Poirier F, Hair M, Bartlett PF, Key B. Role of galectin-1 in the developing mouse olfactory system. Dev Biol 1996; 179: 274-287.

20. Horie $\mathrm{H}$, Inagaki $\mathrm{Y}$, Sohma $\mathrm{Y}$, Nozawa R, Okawa K, Hasegawa M et al. Galectin-1 regulates initial axonal growth in peripheral nerves after axotomy. J Neurosci 1999; 19: 9964-9974.

21. Kajitani K, Yamaguchi H, Dan Y, Furuichi M, Kang D, Nakabeppu Y. MTH1, an oxidized purine nucleoside triphosphatase, suppresses the accumulation of oxidative damage of nucleic acids in the hippocampal microglia during kainate-induced excitotoxicity. J Neurosci 2006; 26: 1688-1698.

22. Royle SJ, Collins FC, Rupniak HT, Barnes JC, Anderson R. Behavioural analysis and susceptibility to CNS injury of four inbred strains of mice. Brain Res 1999; 816: 337-349.
23. Sakaguchi M, Shingo T, Shimazaki T, Okano HJ, Shiwa M, Ishibashi S et al. A carbohydrate-binding protein, galectin-1, promotes proliferation of adult neural stem cells. Proc Natl Acad Sci USA 2006; 103: 7112-7117.

24. Parent JM, Yu TW, Leibowitz RT, Geschwind DH, Sloviter RS, Lowenstein DH. Dentate granule cell neurogenesis is increased by seizures and contributes to aberrant network reorganization in the adult rat hippocampus. J Neurosci 1997; 17: 3727-3738.

25. Jin K, Minami M, Lan JQ, Mao XO, Batteur S, Simon RP et al. Neurogenesis in dentate subgranular zone and rostral subventricular zone after focal cerebral ischemia in the rat. Proc Natl Acad Sci USA 2001; 98: 4710-4715.

26. Jin K, Galvan V, Xie L, Mao XO, Gorostiza OF, Bredesen DE et al. Enhanced neurogenesis

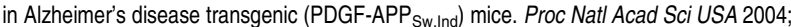
101: 13363-13367.

27. Georgiadis V, Stewart HJ, Pollard HJ, Tavsanoglu Y, Prasad R, Horwood J et al. Lack of galectin-1 results in defects in myoblast fusion and muscle regeneration. Dev Dyn 2007; 236: 1014-1024.

28. Song $\mathrm{H}$, Stevens $\mathrm{CF}$, Gage $\mathrm{FH}$. Astroglia induce neurogenesis from adult neural stem cells. Nature 2002; 417: 39-44.

29. Kempermann G, Jessberger S, Steiner B, Kronenberg G. Milestones of neuronal development in the adult hippocampus. Trends Neurosci 2004; 27: 447-452.

30. Sakaguchi M, Imaizumi Y, Okano H. Expression and function of galectin-1 in adult neural stem cells. Cell Mol Life Sci 2007; 64: 1254-1258.

31. Sasaki T, Hirabayashi J, Manya H, Kasai K, Endo T. Galectin-1 induces astrocyte differentiation, which leads to production of brain-derived neurotrophic factor. Glycobiology 2004; 14: 357-363

32. Lee J, Duan W, Mattson MP. Evidence that brain-derived neurotrophic factor is required for basal neurogenesis and mediates, in part, the enhancement of neurogenesis by dietary restriction in the hippocampus of adult mice. $J$ Neurochem 2002; 82: 1367-1375.

33. Horie H, Kadoya T, Hikawa N, Sango K, Inoue H, Takeshita K et al. Oxidized galectin-1 stimulates macrophages to promote axonal regeneration in peripheral nerves after axotomy. J Neurosci 2004; 24: 1873-1880.

34. Poirier $F$, Robertson EJ. Normal development of mice carrying a null mutation in the gene encoding the L14 S-type lectin. Development 1993; 119: 1229-1236.

35. Yang DD, Kuan CY, Whitmarsh AJ, Rincon M, Zheng TS, Davis RJ et al. Absence of excitotoxicity-induced apoptosis in the hippocampus of mice lacking the Jnk3 gene. Nature 1997; 389: 865-870.

36. Franklin KB, Paxinos G. The Mouse Brain in Stereotaxic Coordinates. Academic Press: New York, 2001

37. Kempermann G, Kuhn HG, Gage FH. Experience-induced neurogenesis in the senescent dentate gyrus. J Neurosci 1998; 18: 3206-3212.

38. Tsuchimoto D, Sakai Y, Sakumi K, Nishioka K, Sasaki M, Fujiwara T et al. Human APE2 protein is mostly localized in the nuclei and to some extent in the mitochondria, while nuclear APE2 is partly associated with proliferating cell nuclear antigen. Nucleic Acids Res 2001; 29: 2349-2360.

39. Lyons SA, Kettenmann $\mathrm{H}$. Oligodendrocytes and microglia are selectively vulnerable to combined hypoxia and hypoglycemia injury in vitro. J Cereb Blood Flow Metab 1998; 18: 521-530.

\section{Supplementary Information accompanies the paper on Cell Death and Differentiation website (http://www.nature.com/cdd)}

